\title{
The BPS domain of Grb10 inhibits the catalytic activity of the insulin and IGF1 receptors
}

\author{
Evan G. Stein ${ }^{\mathrm{a}}$, Thomas A. Gustafson ${ }^{\mathrm{b}}$, Stevan R. Hubbard ${ }^{\mathrm{a}, *}$ \\ a Skirball Institute of Biomolecular Medicine and Department of Pharmacology, New York University School of Medicine, 540 First Avenue, \\ New York, NY 10016, USA \\ ${ }^{\mathrm{b}}$ Metabolex Inc., Hayward, CA 94545, USA
}

Received 1 March 2001; accepted 1 March 2001

First published online 13 March 2001

Edited by Jacques Hanoune

\begin{abstract}
Grb7, Grb10 and Grb14 comprise a family of adaptor proteins that interact with numerous receptor tyrosine kinases upon receptor activation. Between the pleckstrin homology $(\mathrm{PH})$ domain and the Src homology 2 (SH2) domain of these proteins is a region of approximately 50 residues known as the BPS (between $\mathrm{PH}$ and $\mathrm{SH} 2$ ) domain. Here we show, using purified recombinant proteins, that the BPS domain of Grb10 directly inhibits substrate phosphorylation by the activated tyrosine kinase domains of the insulin receptor and the insulin-like growth factor 1 (IGF1) receptor. Although inhibition by the BPS domain is dependent on tyrosine phosphorylation of the kinase activation loop, peptide competition experiments indicate that the BPS domain does not bind directly to phosphotyrosine. These studies provide a molecular mechanism by which Grb10 functions as a negative regulator of insulin- and/or IGF1-mediated signaling. (C) 2001 Published by Elsevier Science B.V. on behalf of the Federation of European Biochemical Societies.
\end{abstract}

Key words: Grb10; Insulin receptor; Insulin-like growth factor 1 receptor; Receptor tyrosine kinase; Enzyme inhibition

\section{Introduction}

Grb10 is a member of a family of adaptor (non-catalytic) proteins including Grb7 and Grb14 which have been identified as putative downstream effectors of activated receptor tyrosine kinases. Proteins in this family contain an $\mathrm{NH}_{2}$-terminal proline-rich region, a Ras-associated-like domain, a pleckstrin homology $(\mathrm{PH})$ domain, a short region known as the BPS (between $\underline{\mathrm{PH}}$ and $\underline{\mathrm{S}} \mathrm{H} 2$ ) domain, and a C-terminal Src homology 2 (SH2) domain. Multiple alternatively spliced forms of Grb10 $(\alpha-\zeta)$ have been cloned from mice, rats and humans [1-6]. Grb10 isoforms have been shown to interact with the insulin receptor (IR) and the insulin-like growth factor 1 receptor (IGF1R) [3-14], as well as with the epidermal growth factor $(E G F)$ receptor $[1,12]$, the platelet-derived growth factor (PDGF) receptor [4,14], Ret [15] and the ephrin receptor EphB2/ELK [16].

Two domains of Grb10 are capable of mediating an interaction with the IR: the BPS domain and the SH2 domain [2$4,8,12]$. The BPS domain of Grb10 has been demonstrated to interact with the core tyrosine kinase domains of the IR and

*Corresponding author. Fax: (1)-212-263 8951.

E-mail: hubbard@tallis.med.nyu.edu
IGF1R in a phosphorylation-dependent manner [12]. The isolated $\mathrm{SH} 2$ domain of Grb10 has been shown to bind to the phosphorylated C-terminal tail of the IR [8]. However, the relevance of this interaction for full-length Grb10 (with the BPS domain present) is questionable, since full-length Grb10 with a non-functional $\mathrm{SH} 2$ domain interacts with the IR to the same extent as wild-type Grb10 [12]. Interestingly, the isolated Grb14 SH2 domain, which is $72 \%$ identical in sequence to the Grb10 SH2 domain, does not interact with the IR $[17,18]$.

The role of Grb10 and Grb14 in insulin and IGF1 signaling is controversial. Overexpression of human Grb10 $\beta$ in Chinese hamster ovary $(\mathrm{CHO})$ cells was shown to reduce insulin-dependent phosphorylation of IR substrate 1 (IRS1) and diminish activation of phosphoinositide-3 kinase [2], providing evidence that Grb10 $\beta$ negatively regulates insulin signaling. Similarly, overexpression of Grb14 in CHO cells was found to inhibit insulin-stimulated DNA and glycogen synthesis [17]. In another study, overexpression of Grb10 $\alpha$ in mouse fibroblast cells inhibited IGF1- but not insulin-stimulated mitogenesis [10]. Paradoxically, other experiments with Grb10 $\alpha$ have shown it to be a positive regulator of both insulin- and IGF1mediated mitogenesis [14]. Microinjection into rat fibroblasts of a Grb10 $\gamma$ deletion protein containing the BPS domain (unknown at the time) and the $\mathrm{SH} 2$ domain partially inhibited insulin- and IGF1-stimulated cell growth [3], which could be consistent with either a negative role for Grb10 $\gamma$ or a positive role (BPS-SH2 acting as a dominant negative).

To better understand the functional consequences of the physical interaction between the BPS domain of Grb10 and the tyrosine kinase domain of the IR (IRK), we have measured the effect of the BPS domain on the catalytic activity of IRK in vitro using purified protein components. We demonstrate that binding of the BPS domain to IRK directly inhibits substrate phosphorylation. Inhibition of IRK by the BPS domain depends on phosphorylation of the IRK activation loop (A-loop), yet the BPS domain does not appear to bind directly to a phosphotyrosine in the A-loop. The BPS domain also inhibited the catalytic activity of autophosphorylated (activated) IGF1R kinase (IGF1RK), but not the activity of autophosphorylated fibroblast growth factor receptor 1 kinase (FGFR1K).

\section{Materials and methods}

\subsection{Production of Grb10 proteins}

Full-length Grb10 $\gamma$ (residues 1-536) and the wild-type and mutant 
(Arg462 $\rightarrow$ Lys) BPS-SH2 constructs (encoding residues 357-536) were subcloned into expression vector pET21 (Novagen). All constructs were verified by DNA sequencing. Escherichia coli strain BL21(DE3) was transformed with the plasmids and cultures were grown in Luria broth at $37^{\circ} \mathrm{C}$ to an $\mathrm{OD}_{600}$ of 0.8 . Protein expression was induced by addition of isopropyl $\beta$-D-thiogalactopyranoside (1.0 $\mathrm{mM}$ final) for $3 \mathrm{~h}$ at $30^{\circ} \mathrm{C}$. Bacteria were harvested by centrifugation, resuspended in lysis buffer (20 mM HEPES ( $\mathrm{pH} 7.5), 0.1 \%$ Triton, $1 \mathrm{mM}$ phenylmethylsulfonyl fluoride, and Complete Protease Inhibitor tablets (Boehringer-Mannheim)), and lysed by French press. The lysate was centrifuged at $20000 \times g$ for $1 \mathrm{~h}$ and the supernatant was collected. Proteins were purified from the soluble fraction using cation-exchange chromatography (Fractogel, EM Science), followed by gel-filtration chromatography (Superdex-75, Pharmacia), and again by cation-exchange chromatography (Mono-S, Pharmacia). Protein concentrations were determined using calculated extinction coefficients [19]. Proteins were stored at $4^{\circ} \mathrm{C}$ at $\sim 10 \mathrm{mg} / \mathrm{ml}$ in $20 \mathrm{mM}$ HEPES (pH 7.5) and $200 \mathrm{mM} \mathrm{NaCl}$.

The isolated Grb10 SH2 domain (both wild-type and the Arg462 $\rightarrow$ Lys mutant) was obtained by mixing purified BPS-SH2 (4 $\mathrm{mg} / \mathrm{ml}$ final) at room temperature with elastase $(10 \mu \mathrm{g} / \mathrm{ml}$ final $)$ for $2.5 \mathrm{~h}$. The resulting proteolyzed fragments were purified by gelfiltration chromatography (Superose-12, Pharmacia). A 12340 Da fragment was verified to be the $\mathrm{SH} 2$ domain (residues 429-533) by mass spectrometry and $\mathrm{NH}_{2}$-terminal sequencing.

\subsection{Production of IRK, IGFIRK, FGFRIK and Shc}

IRK (residues 978-1283) and IRKJ (residues 956-1283) were expressed by recombinant baculovirus in Sf9 cells. IRK and IRKJ contain the substitutions Cys981 $\rightarrow$ Ser and Tyr984 $\rightarrow$ Phe [20]. IRKJ contains in addition the substitution Tyr965 $\rightarrow$ Phe. The IRK and IRKJ mutants were generated using either the Altered-site II system (Promega) or the QuickChange system (Stratagene). All constructs were verified by DNA sequencing. Purification of IRK and IRKJ was performed as described previously [20]. Tris-phosphorylated IRK (IRK ${ }^{3 P}$ : pTyr1158/1162/1163) and tetra-phosphorylated IRKJ (IRKJ ${ }^{4 P}$ : pTyr972/1158/1162/1163) were produced by incubation with Mg-ATP followed by purification on an anion-exchange column (Mono-Q, Pharmacia) [21]. The phosphorylation state of IRK was monitored using native gel electrophoresis [22].

Tris-phosphorylated IGF1RK (prepared similarly to $\operatorname{IRK}^{3 \mathrm{P}}$ ) was provided by S. Favelyukis and W.T. Miller (SUNY Stony Brook). Purified, unphosphorylated FGFR1K from baculovirus-infected Sf9 cells [23] was provided by M. Mohammadi (New York University). FGFR1K was autophosphorylated in vitro by mixing $375 \mu \mathrm{l}$ of FGFR1K $(\sim 25 \mu \mathrm{M}, \mathrm{pH} 7.3)$ with $125 \mu \mathrm{l}$ of $80 \mathrm{mM}$ ATP and 200 $\mathrm{mM} \mathrm{MgCl} 2$ for $40 \mathrm{~min}$ at room temperature. Autophosphorylated FGFR1K was then purified by anion-exchange chromatography (Mono-Q, Pharmacia). The activity of autophosphorylated FGFR1K was approximately 500 times that of unphosphorylated FGFR1K. The recombinant baculovirus for full-length Shc (p52) was provided by $\mathrm{M}$. Mohammadi. The Shc protein, which contains an $\mathrm{NH}_{2}$-terminal histidine tag, was purified from baculovirus-infected Sf9 cells to $>90 \%$ purity using Ni-affinity chromatography (Qiagen).

\subsection{Peptide substrate and Shc phosphorylation assays}

The peptide substrate KKLATGDYMNMSP was derived from phosphorylation site Tyr727 of rat IRS1. The peptide was commercially synthesized (Alpha Diagnostic Int.) and purified by high-performance liquid chromatography (HPLC) on a C-18 reverse-phase column (Vydac). The peptide identity was confirmed by mass spectrometry. Kinase assays were performed in triplicate in a water bath maintained at $30^{\circ} \mathrm{C}$. Reactions were initiated by the addition of 12.5 $\mu \mathrm{l}$ of a solution containing $400 \mu \mathrm{M}$ ATP, $100 \mathrm{mM}$ HEPES (pH 7.5), $40 \mathrm{mM} \mathrm{MgCl} 2,2 \mathrm{mM}$ of the peptide substrate and $\left[\gamma^{32} \mathrm{P}\right]$ ATP to 12.5 $\mu \mathrm{l}$ of a solution containing 0.2 or $0.4 \mu \mathrm{M}$ of the appropriate kinase and the appropriate form of Grb10 (full-length, BPS-SH2WT , BPS$\mathrm{SH} 2^{\mathrm{R} 462 \mathrm{~K}}$ or $\mathrm{SH} 2^{\mathrm{WT}}$ ) at either $0,2,20$ or $200 \mu \mathrm{M}$. Reactions were terminated after $20 \mathrm{~min}$ by the addition of $25 \mu \mathrm{l}$ of $30 \%$ trichloroacetic acid. The reactions were then centrifuged at $14000 \times g$ for $2 \mathrm{~min}$, and $50 \mu \mathrm{l}$ aliquots were spotted onto $2.1 \mathrm{~cm}$ diameter phosphocellulose paper discs (P81, Whatman). The discs were washed collectively three times for $10 \mathrm{~min}$ with $0.5 \%$ phosphoric acid and rinsed once in acetone. The discs were air-dried and placed in $1.5 \mathrm{ml}$ tubes for scintilla- tion counting. All measurements of kinase activity were performed under initial rate conditions.

Shc phosphorylation assays were performed in triplicate at room temperature. Reactions were initiated by the addition of $7.5 \mu \mathrm{l}$ of a solution containing $600 \mu \mathrm{M}$ ATP, $100 \mathrm{mM}$ HEPES (pH 7.5), $5 \mathrm{mM}$ $\mathrm{MgCl}_{2}, 26 \mu \mathrm{M}$ Shc and $\left[\gamma^{-32} \mathrm{P}\right] \mathrm{ATP}$ to $2.5 \mu \mathrm{l}$ of a solution containing $1 \mu \mathrm{M}$ IRKJ JP $^{4 \mathrm{P}}$ and BPS-SH2 $2^{\mathrm{R} 462 \mathrm{~K}}$ at either $0,5,50$ or $200 \mu \mathrm{M}$. Reactions were terminated after $10 \mathrm{~min}$ by the addition of $10 \mu \mathrm{l}$ of Laemmli sample buffer (Bio-Rad). The reactions were then run on a $12.5 \%$ polyacrylamide gel. The gel was then dried and exposed to a phosphor screen (Molecular Dynamics) for $1 \mathrm{~h}$. The screen was scanned by a Storm-820 phosphorimager (Molecular Dynamics), and the resulting image was analyzed using ImageQuant software (Molecular Dynamics) to quantify the intensity of the bands.

\subsection{Gel shift assays}

$1 \mu \mathrm{l}$ of purified $\mathrm{BPS}-\mathrm{SH} 2^{\mathrm{WT}}$, BPS-SH2 $2^{\mathrm{R} 462 \mathrm{~K}}$ or SH2 $2^{\mathrm{WT}}$ at $300 \mu \mathrm{M}$ was mixed with $1 \mu \mathrm{l}$ of $\mathrm{IRK}^{0 \mathrm{P}}$ or IRK ${ }^{3 \mathrm{P}}$ at $80 \mu \mathrm{M}$. For the peptide competition assays, $1 \mu \mathrm{l}$ of purified BPS-SH $2^{\mathrm{WT}}$ or BPS-SH2 $2^{\mathrm{R} 462 \mathrm{~K}}$ at $200 \mu \mathrm{M}$ was mixed with $2 \mu \mathrm{l}$ of $\mathrm{IRK}^{3 \mathrm{P}}$ at $100 \mu \mathrm{M}$ and $1 \mu \mathrm{l}$ of a trisphosphorylated A-loop peptide $\left(\mathrm{AL}^{3 \mathrm{P}}\right)$ at $64,320,1600$ or $8000 \mu \mathrm{M}$. Mixtures were loaded onto $20 \%$ native PhastGels and electrophoresed with the PhastGel system (Pharmacia). The gels were stained with PhastGel Blue R. A peptide corresponding to residues 1156-1168 of the IRK A-loop (DIYETDYYRKGGK) was synthesized on a 431A Peptide Synthesizer (Applied Biosystems) and phosphorylated in vitro by $\mathrm{IRK}^{3 \mathrm{P}}$. AL ${ }^{3 \mathrm{P}}$ was purified by HPLC on a C-18 reverse-phase column (Vydac). The phosphorylation state of the peptide was verified by mass spectrometry.

\section{Results}

\subsection{A functional SH2 domain is not necessary for the binding of Grb10 to IRK}

Based upon previously published data establishing that the BPS and SH2 domains of Grb10 are capable of mediating an interaction with the IR [2-4,8,12], we overexpressed and purified to homogeneity two forms of a Grb10 $\gamma$ deletion mutant consisting of the BPS and SH2 domains (BPS-SH2). The first form contains a wild-type $\mathrm{SH} 2$ domain (BPS-SH2 ${ }^{\mathrm{WT}}$ ) and the second form contains an arginine to lysine substitution (Arg462 $\rightarrow$ Lys) in the FLVR motif of the SH2 domain (BPS-SH2 $2^{\mathrm{R} 462 \mathrm{~K}}$ ). This substitution has been shown to abrogate the interaction between the Grb10 SH2 domain and the IR [12]. In addition, the isolated wild-type and mutant $\mathrm{SH} 2$ domains $\left(\mathrm{SH} 2^{\mathrm{WT}}\right.$ and $\mathrm{SH} 2^{\mathrm{R} 462 \mathrm{~K}}$ ) were generated. Attempts to overexpress and purify the isolated BPS domain were not successful, probably owing to protein folding difficulties.

We performed native gel shift experiments to monitor the binding of the BPS-SH2 proteins (BPS-SH2 ${ }^{\mathrm{WT}}$ and BPS$\mathrm{SH} 2^{\mathrm{R} 462 \mathrm{~K}}$ ) to IRK. IRK contains three autophosphorylation sites (Tyr1158/1162/1163), all of which are located in the kinase A-loop. The results shown in Fig. 1A demonstrate that BPS-SH2 ${ }^{\text {WT }}$ and BPS-SH $2^{\mathrm{R} 462 \mathrm{~K}}$ bind to the tris-phosphorylated, activated form of IRK (IRK ${ }^{3 P}$ ) with approximately equal affinity and do not bind to unphosphorylated IRK $\left(\mathrm{IRK}^{0 \mathrm{P}}\right)$, consistent with previous yeast two-hybrid and glutathione $S$-transferase pull-down experiments [12]. Mixing of isolated $\mathrm{SH} 2^{\mathrm{WT}}$ with $\mathrm{IRK}^{3 \mathrm{P}}$ produced a smear on a native gel (Fig. 1A, last lane), which suggests a low affinity interaction, while $\mathrm{SH} 2^{\mathrm{R} 462 \mathrm{~K}}$ produced no shift or smear (data not shown). These experiments show that the phosphotyrosinebinding function of the $\mathrm{SH} 2$ domain is not required for BPS-SH2 binding to IRK ${ }^{3 P}$; the BPS domain is sufficient for this interaction. 

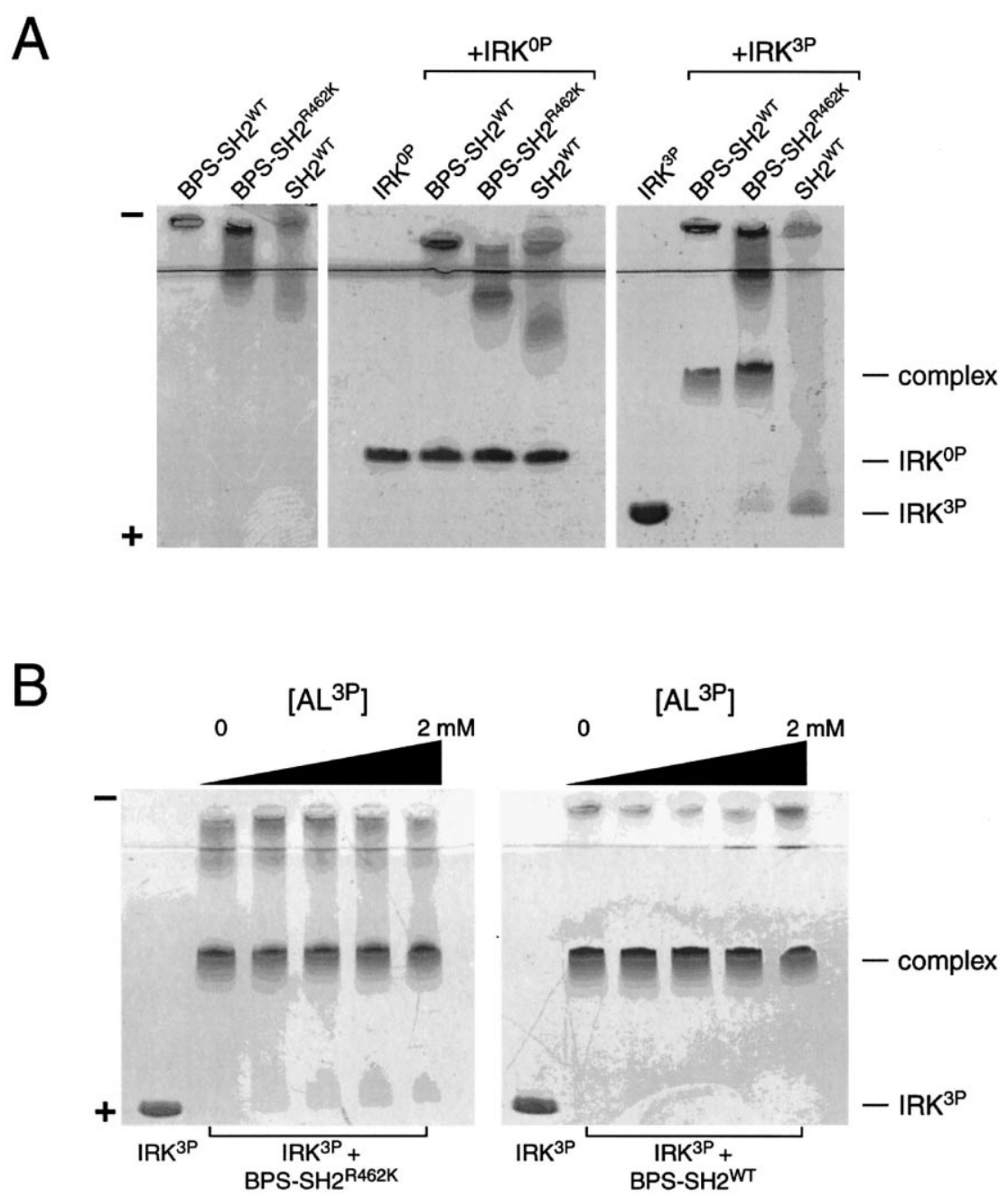

Fig. 1. The BPS-SH2 protein binds $\mathrm{IRK}^{3 \mathrm{P}}$ but not an A-loop phosphotyrosine. (A) The ability of BPS-SH2 $2^{\mathrm{WT}}$, BPS-SH2 $2^{\mathrm{R} 462 \mathrm{~K}}$ and $\mathrm{SH} 2^{\mathrm{WT}}$ to bind $\mathrm{IRK}^{0 \mathrm{P}}$ and $\mathrm{IRK}^{3 \mathrm{P}}$ was assayed by native gel shift as described in Section 2 . The Grb10 proteins do not migrate into the gel due to their high $\mathrm{p}$ I. IRK ${ }^{3 \mathrm{P}}$ migrates further than IRK ${ }^{0 \mathrm{P}}$ due to the additional negative charges provided by the phosphates. Mixing of BPS-SH2WT or BPS-SH2 $2^{\mathrm{R} 462 \mathrm{~K}}$ to $\mathrm{IRK}^{3 \mathrm{P}}$ produced a new band (labeled 'complex') corresponding to the complex of BPS-SH2 and IRK ${ }^{3 \mathrm{P}}$. Mixing of SH2 $2^{\mathrm{WT}}$ with $\mathrm{IRK}^{3 \mathrm{P}}$ results in the disappearance of the $\mathrm{IRK}^{3 \mathrm{P}}$ band, but not in the appearance of a distinct band representing an $\mathrm{SH}_{2}{ }^{\mathrm{WT}}-\mathrm{IRK}^{3 \mathrm{P}}$ complex. (B) $\mathrm{AL}^{3 \mathrm{P}}$ was used to compete with $\mathrm{IRK}^{3 \mathrm{P}}$ for binding to BPS-SH2. In each of the lanes of the non-denaturing gel, IRK ${ }^{3 \mathrm{P}}$ and $\mathrm{BPS}-$ SH2, either mutant (left panel) or wild-type (right panel), are at a concentration of $50 \mu \mathrm{M}$. The peptide concentrations are 0 , 16, 80,400 and $2000 \mu \mathrm{M}$.

\subsection{The BPS domain of Grb10 does not bind directly to an IRK phosphotyrosine}

Having established that the BPS domain binds to IRK in a phosphorylation-dependent manner, we tested whether the BPS domain interacts directly with one or more phosphotyrosines in the IRK A-loop by performing a peptide competition experiment using $\mathrm{AL}^{3 \mathrm{P}}$. As shown in Fig. $1 \mathrm{~B}, \mathrm{AL}^{3 \mathrm{P}}$ up to a concentration of $2 \mathrm{mM}\left(40 \times\right.$ molar excess over IRK $\left.^{3 \mathrm{P}}\right) \mathrm{did}$ not disrupt the complex between BPS-SH2 $2^{\mathrm{R} 462 \mathrm{~K}}$ and $\mathrm{IRK}^{3 \mathrm{P}}$, indicating that the phosphorylated A-loop is not the primary site of interaction between the BPS domain and IRK ${ }^{3 P}$. Furthermore, $\mathrm{AL}^{3 \mathrm{P}}$ did not disrupt the binding of $\mathrm{BPS}-\mathrm{SH} 2^{\mathrm{WT}}$ to $\mathrm{IRK}^{3 \mathrm{P}}$ (Fig. 1B), providing additional evidence that the BPS domain, not the $\mathrm{SH} 2$ domain, mediates the interaction with $\mathrm{IRK}^{3 \mathrm{P}}$.

\subsection{The BPS domain of Grb10 inhibits substrate phosphorylation by IRK}

To determine what effect, if any, binding of the BPS do- main to $\mathrm{IRK}^{3 \mathrm{P}}$ has on tyrosine kinase activity, we performed kinase assays in the presence of various amounts of BPS-SH2. As shown in Fig. 2A, BPS-SH2 ${ }^{\text {WT }}$ inhibited substrate phosphorylation by $\mathrm{IRK}^{3 \mathrm{P}}$ in a concentration-dependent manner. Consistent with the gel shift experiments (which showed similar binding), BPS-SH2 $2^{\mathrm{R} 462 \mathrm{~K}}$ inhibited substrate phosphorylation to the same extent as BPS-SH2 ${ }^{\mathrm{WT}}$. The observed inhibition by BPS-SH2 is not simply due to substrate competition, since BPS-SH2 is not a substrate of IRK as assessed by antiphosphotyrosine Western blotting and autoradiography (data not shown).

The isolated wild-type SH2 domain had no effect on $\mathrm{IRK}^{3 \mathrm{P}}$ substrate phosphorylation (Fig. 2A), either because of poor binding (Fig. 1A, last lane) or because binding of the $\mathrm{SH} 2$ domain to the phosphorylated A-loop does not result in kinase inhibition. This result indicates that the BPS domain of the BPS-SH2 protein is responsible for the inhibitory effect. To verify that full-length $\mathrm{Grb} 10 \gamma\left(\mathrm{Grb} 10^{\mathrm{FL}}\right)$ also inhibits IRK catalytic activity, we performed kinase assays in the presence 
A

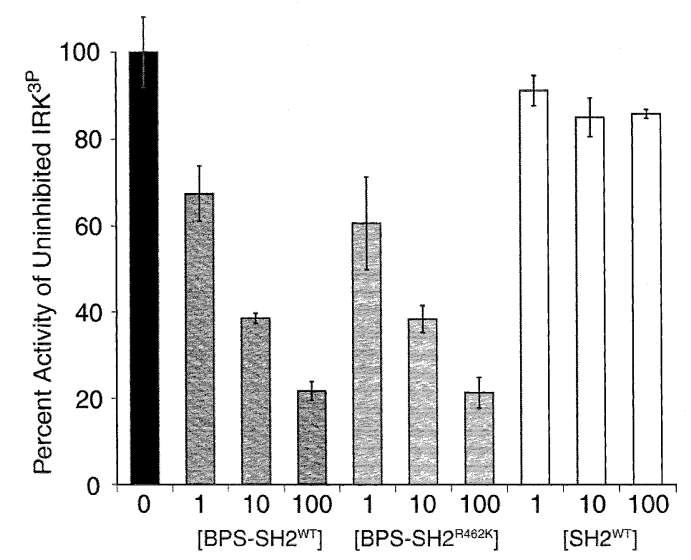

B

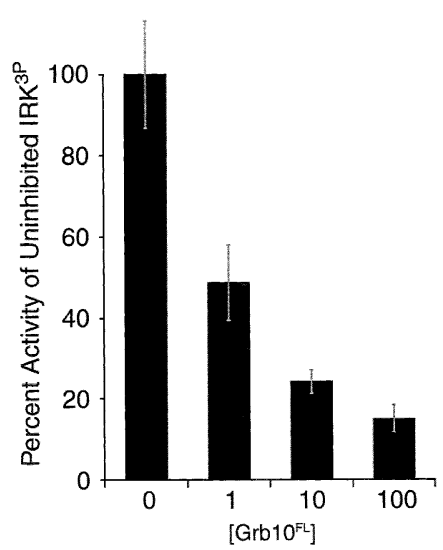

Fig. 2. The BPS domain of Grb10 inhibits peptide phosphorylation by IRK ${ }^{3 P}$. (A) The activity of purified IRK ${ }^{3 P}$ was assayed in the presence of the indicated concentrations of BPS-SH2 ${ }^{\mathrm{WT}}$ (dark gray), BPS-SH2 ${ }^{\mathrm{R} 462 \mathrm{~K}}$ (light gray) and $\mathrm{SH} 2^{\mathrm{WT}}$ (white). Activity was assayed using $100 \mathrm{nM}$ $\mathrm{IRK}^{3 \mathrm{P}}$ and $1 \mathrm{mM}$ of peptide substrate (see Section 2). IRK ${ }^{3 \mathrm{P}}$ activity in the presence of the Grb10 proteins is expressed as a percentage of the activity of $\mathrm{IRK}^{3 \mathrm{P}}$ alone (black). The mean and standard deviation are derived from triplicate experiments. (B) The same assay was performed in triplicate using Grb10 $\mathrm{FL}$.

of various amounts of Grb10 $0^{\mathrm{FL}}$. The results presented in Fig. $2 \mathrm{~B}$ show that Grb10 $0^{\mathrm{FL}}$, like the BPS-SH2 protein, also inhibits $\mathrm{IRK}^{3 \mathrm{P}}$ substrate phosphorylation in a dose-dependent manner.

To examine the effect of the BPS domain on IRK phosphorylation of a bona fide protein substrate, we used Shc (p52) as a substrate. Shc is recruited to the activated IR via an interaction between the phosphotyrosine-binding (PTB) domain of Shc and pTyr972 in the juxtamembrane region of the IR [24,25]. Accordingly, an IR cytoplasmic protein that includes the juxtamembrane region as well as the tyrosine kinase domain was produced and tetra-phosphorylated $\left(\mathrm{IRKJ}^{4 \mathrm{P}}\right)$. As shown in Fig. 3, BPS-SH2 $2^{\mathrm{R} 462 \mathrm{~K}}$ inhibited Shc phosphorylation by IRKJ $^{4 \mathrm{P}}$ in a concentration-dependent manner.

\subsection{The BPS domain of Grb10 inhibits substrate phosphorylation by IGF1RK but not FGFRIK}

To begin to explore the kinase selectivity of BPS domain inhibition, the effect of the BPS domain on the catalytic activity of IGF1RK and FGFR1K was examined. BPS$\mathrm{SH} 2^{\mathrm{R} 462 \mathrm{~K}}$ inhibited the catalytic activity of autophosphorylated (activated) IGF1RK in a concentration-dependent manner (Fig. 4), similar to inhibition of IRK $^{3 P}$ (Fig. 2A), but did not affect the catalytic activity of autophosphorylated FGFR1K (data not shown). The inability of BPS-SH2 $2^{\mathrm{R} 462 \mathrm{~K}}$ to inhibit autophosphorylated FGFR1K demonstrates that the BPS-SH2 preparation is not deleterious to kinase activity per se, and indicates that the BPS domain selectively inhibits tyrosine kinase activity.

Inhibition of IGF1RK was not surprising because it is $\sim 80 \%$ identical in sequence to IRK, and Grb10 has been shown previously to interact with the IGF1R $[3,7,9,10,12]$. Although FGFR1K is only $\sim 40 \%$ identical in sequence to IRK, its A-loop contains two tyrosines, Tyr653 and Tyr654, which correspond to Tyr1162 and Tyr1163 in IRK. The observation that the BPS domain of Grb10 is neither able to bind to nor inhibit autophosphorylated FGFR1K further suggests that the primary interaction between the BPS domain and IRK/IGF1RK is not through an A-loop phosphotyrosine.

\section{Discussion}

Previous studies have implicated the $\mathrm{SH} 2$ and BPS domains of Grb10 as mediating the interaction with the activated IR and IGF1R [2-4,8,12]. Although the isolated SH2 domain of Grb10 has been shown previously to be capable of interacting with the IR $[4,8,12]$, two lines of evidence suggest that in fulllength Grb10 the BPS domain is primarily responsible for the interaction. First, yeast two-hybrid experiments indicate that Grb10 $\gamma$ proteins containing a wild-type $\mathrm{SH} 2$ domain or an SH2 domain with a FLVR mutation (Arg462 $\rightarrow$ Lys) interact with the entire IR cytoplasmic domain to the same extent [12]. In that study, the isolated BPS domain interacted less well $(\sim 50 \%)$ with the IR cytoplasmic domain than did BPS$\mathrm{SH} 2^{\mathrm{R} 462 \mathrm{~K}}$, which could be explained by a difficulty in folding of the BPS domain in the absence of the $\mathrm{SH} 2$ domain.

The second line of evidence comes from peptide competition experiments. Here we demonstrated that $\mathrm{AL}^{3 \mathrm{P}}$ was noncompetitive against $\mathrm{IRK}^{3 \mathrm{P}}$ for binding the BPS-SH2 ${ }^{\mathrm{WT}}$ protein (Fig. 1B), indicating that any $\mathrm{SH} 2-$ phosphotyrosine interaction makes a negligible contribution to the overall binding of BPS-SH2 $2^{\mathrm{WT}}$ to $\mathrm{IRK}^{3 \mathrm{P}}$. Moreover, phosphorylated peptides derived from the juxtamembrane region, the A-loop and the C-terminal tail of the IR did not have any significant effect on binding of Grb10 $\gamma$ to the full-length IR [4]. Taken together, these studies suggest that the $\mathrm{SH} 2$ domain in fulllength Grb10 may not engage a phosphotyrosine in the IR cytoplasmic domain, or if so, the interaction may be of minor importance.

The peptide competition experiments with $\mathrm{AL}^{3 \mathrm{P}}$ demonstrate that the predominant mode of binding of the BPS domain to IRK is not via the phosphorylated A-loop (Fig. 1B), suggesting instead that a binding epitope for the BPS domain is exposed upon autophosphorylation of the A-loop. Crystal structures of IRK $^{0 \mathrm{P}}$ (low activity) [20] and IRK $^{3 \mathrm{P}}$ (activated) [21] reveal that the A-loop undergoes a major conformational 
change upon autophosphorylation. In the crystal structure of $\mathrm{IRK}^{3 \mathrm{P}}$, pTyr1163 is observed to be the key phosphotyrosine in stabilization of the A-loop conformation, followed by pTyr1162 and pTyr1158 [21]. Inhibition by BPS-SH2 of the three bis-phosphorylated A-loop forms of IRK correlates well with the degree of A-loop stabilization afforded by autophosphorylation at the three sites (data not shown).

Based on the gel shift assays, the dissociation constant $\left(K_{\mathrm{d}}\right)$ for the interaction between the BPS domain (in the BPS-SH2 protein) and $\mathrm{IRK}^{3 \mathrm{P}}$ is estimated to be on the order of $1 \mu \mathrm{M}$. Although its ligand has not been determined, the PH domain of Grb10 presumably binds to the phosphorylated head groups of phosphatidylinositol lipids [26]. Localization of Grb10 to the membrane via the PH domain would significantly enhance the interaction between the BPS domain and the activated IR by increasing the effective concentration of Grb10. It may be that different subsets of the various domains of Grb10 family members (poly-proline, Ras-associated-like, $\mathrm{PH}, \mathrm{BPS}$ and SH2) are utilized depending on the particular receptor tyrosine kinase that has been activated. For example, the $\mathrm{SH} 2$ domain rather than the BPS domain mediates the interaction of Grb10 with the EGF [1,12] and PDGF [4,14] receptors.

Many proteins containing SH2 and PTB domains are re-
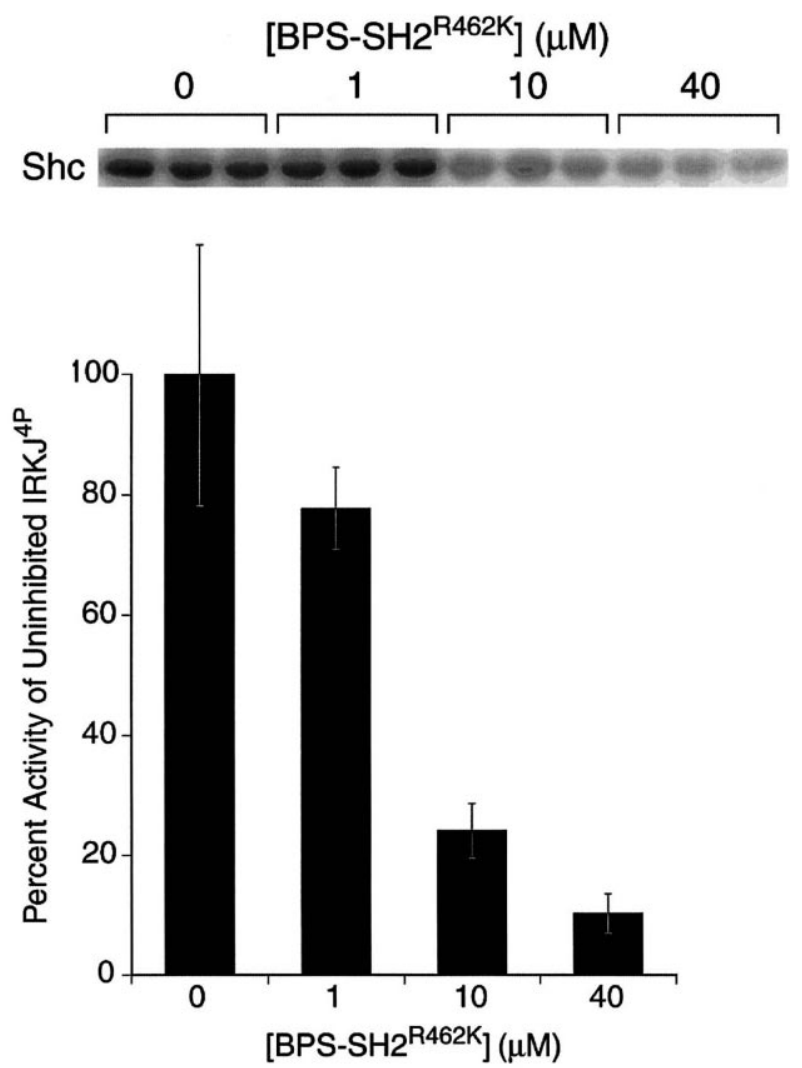

Fig. 3. The BPS domain of Grb10 inhibits phosphorylation of Shc by IRKJ ${ }^{4 \mathrm{P}}$. The activity of purified IRKJ ${ }^{4 \mathrm{P}}$ was assayed in the presence of the indicated concentrations of BPS-SH2 $2^{\mathrm{R} 462 \mathrm{~K}}$. Activity was assayed using $200 \mathrm{nM}$ IRKJ $^{4 \mathrm{P}}$ and $20 \mu \mathrm{M}$ of Shc (see Section 2). The reaction mixture was electrophoresed on a $12.5 \%$ polyacrylamide gel and the resulting autoradiograph is shown (top panel). Band intensities were quantified and average intensities and standard deviations were determined. IRK $\mathrm{J}^{4 \mathrm{P}}$ activity in the presence of BPS-SH2 $2^{\mathrm{R} 462 \mathrm{~K}}$ is expressed as a percentage of the activity of IRKJ $^{4 P}$ alone (bottom panel).

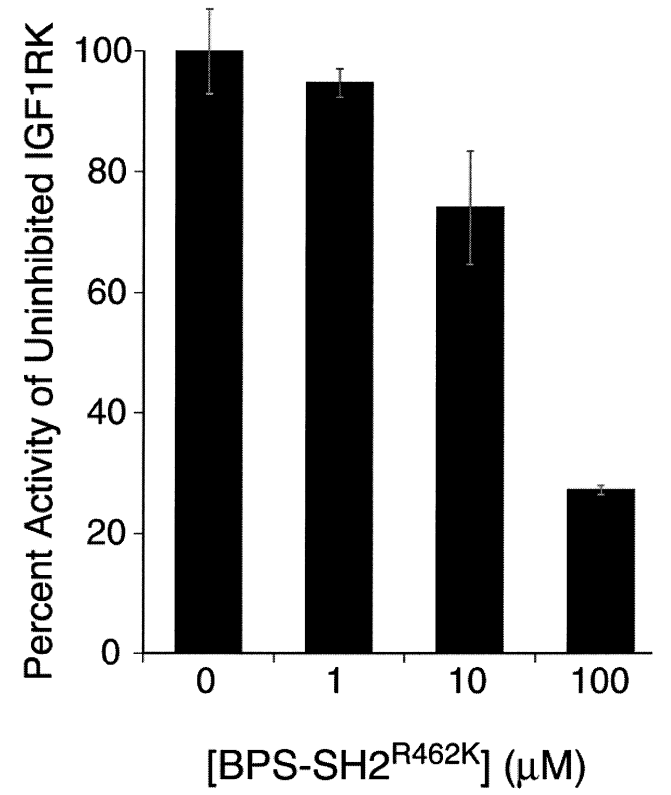

Fig. 4. The BPS domain of Grb10 inhibits IGF1RK. The activity of autophosphorylated IGF1RK was assayed in the presence of the indicated concentrations of BPS-SH $2^{\mathrm{R} 462 \mathrm{~K}}$. Activity was assayed using $200 \mathrm{nM}$ of IGF1RK and $1 \mathrm{mM}$ of peptide substrate (see Section 2). The mean and standard deviation are derived from triplicate experiments. The activity of IGF1RK in the presence of BPS-SH $2^{\mathrm{R} 462 \mathrm{~K}}$ is expressed as a percentage of IGF1RK alone.

cruited to activated receptor tyrosine kinases. In general, the phosphotyrosine recruitment sites are outside of the core tyrosine kinase domain of the receptors, in the juxtamembrane, kinase insert and C-terminal regions. Since the BPS domain of Grb10 has been shown previously [12] and in our studies to interact with IRK and IGF1RK, the question arises as to whether binding of the BPS domain to these kinases affects catalytic activity, either positively or negatively. The results presented in this study (Figs. 2-4) demonstrate that binding of the BPS domain to autophosphorylated IRK and IGF1RK negatively affects the ability of these kinases to phosphorylate substrates. The effect on catalytic activity was observed for full-length Grb10 $\gamma$ as well as for BPS-SH2 $2^{\mathrm{R} 462 \mathrm{~K}}$.

Our finding that the BPS domain of Grb10 $\gamma$ directly inhibits IR and IGF1R substrate phosphorylation suggests that Grb10 could act as a negative regulator of processes dependent on tyrosine phosphorylation by these receptors, such as mitogenesis and glucose uptake. This would be consistent with the majority of Grb10 and Grb14 overexpression studies (Section 1). Moreover, in support of the inhibitory mechanism proposed here, it has been reported that overexpression of Grb10 $\beta$ in $\mathrm{CHO}$ cells partially inhibits insulin-stimulated tyrosine phosphorylation of IRS1 and significantly inhibits tyrosine phosphorylation of the p60 GAP-associated protein [2]. In another study, IGF1-stimulated phosphorylation of IRS1 and Shc was not affected by Grb10 $\alpha$ overexpression in p6 cells [10]. In that study, although Grb10 $\alpha$ inhibited IGF1-stimulated mitogenesis, it did not inhibit insulin-stimulated mitogenesis. This suggests that the differences in substrate phosphorylation reported in these two studies [2,10] could be due to the different Grb10 isoforms expressed and/or the cell line used.

We would anticipate that Grb10, acting as an inhibitory binding protein for the IR and IGF1R, would have a differ- 
ential effect on substrate phosphorylation. Because Grb10 and substrate proteins such as IRS1, Shc and p60 GAP-associated protein are all recruited to the IR (or IGF1R) after receptor activation, the degree to which a substrate protein is phosphorylated by the receptor will depend on how rapidly it is recruited to the receptor vis-a-vis recruitment of Grb10 (and other inhibitory proteins such as tyrosine phosphatases). Receptor recruitment is dependent on the particular modular domains ( $\mathrm{SH} 2, \mathrm{PH}, \mathrm{PTB})$ present in the substrate protein (among other factors). Certain substrates are likely to translocate to the activated IR relatively rapidly and would thus be less susceptible to the inhibitory effect of Grb10 than other substrates.

An important clue to the physiological function of Grb10 comes from the discovery that the murine Grb10 gene is maternally imprinted [27]. Such genes typically encode proteins that negatively regulate fetal growth [28]. Moreover, the location of the human Grb10 gene on chromosome 7 [29] makes it a candidate gene underlying Silver-Russell syndrome. This disease is characterized by pre- and postnatal growth retardation and can be caused by maternal disomy of chromosome 7 , which potentially doubles the Grb10 dosage [27]. Our results provide a direct physical mechanism by which Grb10 functions as a negative regulator of insulin- and/or IGF1-mediated signaling.

Acknowledgements: We thank W.T. Miller, M. Mohammadi, S. Li and J. Till for manuscript comments; M. Mohammadi for the Shc baculovirus and purified FGFR1K; S. Favelyukis and W.T. Miller for purified IGF1RK; J. Till for production of bis-phosphorylated IRK proteins; S. Li for purified Shc; and M. Jani for site-directed mutagenesis. This work was supported by NIH Grant DK52916 (S.R.H.).

\section{References}

[1] Ooi, J., Yajnik, V., Immanuel, D., Gordon, M., Moskow, J.J., Buchberg, A.M. and Margolis, B. (1995) Oncogene 10, 16211630.

[2] Liu, F. and Roth, R.A. (1995) Proc. Natl. Acad. Sci. USA 92, 10287-10291.
[3] O’Neill, T.J., Rose, D.W., Pillay, T.S., Hotta, K., Olefsky, J.M. and Gustafson, T.A. (1996) J. Biol. Chem. 271, 22506-22513.

[4] Frantz, J.D., Giorgetti-Peraldi, S., Ottinger, E.A. and Shoelson, S.E. (1997) J. Biol. Chem. 272, 2659-2667.

[5] Laviola, L. et al. (1997) J. Clin. Invest. 99, 830-837.

[6] Dong, L.Q. et al. (1997) J. Biol. Chem. 272, 29104-29112.

[7] Morrione, A., Valentinis, B., Li, S., Ooi, J.Y., Margolis, B. and Baserga, R. (1996) Cancer Res. 56, 3165-3167.

[8] Hansen, H., Svensson, U., Zhu, J., Laviola, L., Giorgino, F., Wolf, G., Smith, R.J. and Riedel, H. (1996) J. Biol. Chem. 271, 8882-8886.

[9] Dey, B.R., Frick, K., Lopaczynski, W., Nissley, S.P. and Furlanetto, R.W. (1996) Mol. Endocrinol. 10, 631-641.

[10] Morrione, A., Valentinis, B., Resnicoff, M., Xu, S. and Baserga, R. (1997) J. Biol. Chem. 272, 26382-26387.

[11] Dong, L.Q., Farris, S., Christal, J. and Liu, F. (1997) Mol. Endocrinol. 11, 1757-1765.

[12] He, W., Rose, D.W., Olefsky, J.M. and Gustafson, T.A. (1998) J. Biol. Chem. 273, 6860-6867.

[13] Liu, F. and Roth, R.A. (1998) Mol. Cell. Biochem. 182, 73-78.

[14] Wang, J. et al. (1999) Mol. Cell. Biol. 19, 6217-6228.

[15] Pandey, A., Duan, H., Di Fiore, P.P. and Dixit, V.M. (1995) J. Biol. Chem. 270, 21461-21463.

[16] Stein, E., Cerretti, D.P. and Daniel, T.O. (1996) J. Biol. Chem. 271, 23588-23593.

[17] Kasus-Jacobi, A., Perdereau, D., Auzan, C., Clauser, E., Van Obberghen, E., Mauvais-Jarvis, F., Girard, J. and Burnol, A.F. (1998) J. Biol. Chem. 273, 26026-26035.

[18] Kasus-Jacobi, A., Bereziat, V., Perdereau, D., Girard, J. and Burnol, A.F. (2000) Oncogene 19, 2052-2059.

[19] Pace, C.N., Vajdos, F., Fee, L., Grimsley, G. and Gray, T. (1995) Protein Sci. 4, 2411-2423.

[20] Hubbard, S.R., Wei, L., Ellis, L. and Hendrickson, W.A. (1994) Nature 372, 746-754.

[21] Hubbard, S.R. (1997) EMBO J. 16, 5572-5581.

[22] Wei, L., Hubbard, S.R., Hendrickson, W.A. and Ellis, L. (1995) J. Biol. Chem. 270, 8122-8130.

[23] Mohammadi, M., Schlessinger, J. and Hubbard, S.R. (1996) Cell $86,577-587$.

[24] Gustafson, T.A., He, W., Craparo, A., Schaub, C.D. and O’Neill, T.J. (1995) Mol. Cell. Biol. 15, 2500-2508.

[25] Isakoff, S.J. et al. (1996) J. Biol. Chem. 271, 3959-3962.

[26] Lemmon, M.A., Ferguson, K.M. and Schlessinger, J. (1996) Cell 85, 621-624.

[27] Miyoshi, N. et al. (1998) Proc. Natl. Acad. Sci. USA 95, 1102 1107.

[28] Tilghman, S.M. (1999) Cell 96, 185-193.

[29] Jerome, C.A., Scherer, S.W., Tsui, L.C., Gietz, R.D. and TriggsRaine, B. (1997) Genomics 40, 215-216. 